\title{
AVALIAÇÃO DA CARGA DE TRABALHO FÍSICO EXIGIDO EM OPERAÇÕES DE PRODUÇÃO DE MUDAS ORNAMENTAIS NO DISTRITO FEDERAL - ESTUDO DE CASO ${ }^{1}$
}

\begin{abstract}
Nilton Cesar Fiedler ${ }^{2}$, Antônio Henrique S. Ferreira ${ }^{3}$, Fábio Venturoli ${ }^{3}$ e Luciano José Minette ${ }^{4}$
RESUMO - Esta pesquisa teve como objetivos a avaliar da carga de trabalho físico exigida em operações de produção de mudas em viveiros que abastecem os canteiros ornamentais do Distrito Federal e classificar as atividades desenvolvidas no viveiro, conforme a sua exigência física, propondo uma reorganização ergonômica para melhoria dos níveis de segurança, saúde, bem-estar e satisfação dos trabalhadores. A carga de trabalho físico foi avaliada por intermédio do levantamento da freqüência cardíaca durante a jornada de trabalho nas diversas fases do ciclo de trabalho, segundo a metodologia proposta por Apud (1997), nas atividades de enchimento dos recipientes plásticos com substrato, abastecimento da carreta com os recipientes plásticos, encanteiramento, plantio de mudas e expedição. Com base nos dados coletados, foram calculadas as médias das frequiências cardíacas das cinco etapas analisadas. De acordo com os resultados obtidos, a freqüência cardíaca média das etapas foi de 97,96 bpm para a fase de enchimento dos recipientes, de 111,7 bpm para o abastecimento da carreta, de $126,26 \mathrm{bpm}$ para o encanteiramento, de $90,75 \mathrm{bpm}$ para o plantio das mudas nos recipientes e de 115,01 bpm para a expedição. A atividade de encanteiramento ultrapassou a carga cardiovascular máxima de $40 \%$, sendo necessário, portanto, um repouso de $12,8 \mathrm{~min}$ por hora trabalhada durante a jornada de trabalho. A maior exigência física no trabalho foi verificada nos trabalhadores que exercem a função de encanteiramento (trabalho físico pesado), seguido do abastecimento da carreta e expedição (ambos moderadamente pesados). As atividades de enchimento dos recipientes e plantio das mudas nos recipientes tiveram a exigência física classificada como leve.
\end{abstract}

Palavras-chave: Carga de trabalho físico, ergonomia florestal e produção de mudas.

\section{EVALUATION OF THE DEMANDED PHYSICAL EFFORT IN ORNAMENTAL NURSERY OPERATIONS IN THE FEDERAL DISTRICT - A CASE STUDY}

\begin{abstract}
The objective of this work was to evaluate the physical work demanded in operations of seedling production in an ornamental nursery that supply gardens in the Federal District, Brazil, and to classify the activities developed according to its physical effort demand proposing an ergonomic reorganization to improve the security levels, health, well-being and satisfaction of workers. Mean cardiac frequencies were calculated for the 5 analyzed stages (polythene bag filling, cart stacking, transport of seedlings in polythene bags to nursery beds, planting of seedlings into bags and shipping). The mean cardiac frequency at the different stages were; $97.96 \mathrm{bpm}$ for polythene bag filling, 111.7 bpm for cart stacking, 126.26 bpm for transport of seedlings in polythene bags to nursery beds, 90.75 bpm for planting of seedlings into polythene bags, and 115.01 bpm for the shipping. Transport of seedlings in polythene bags to nursery beds exceeded the maximum cardiac load, which is $40 \%$, being necessary therefore a rest of 12.8 minutes during the working hours. The heaviest physical effort in the work was found for the operation transport of seedlings in polythene bags to nursery beds (heavy physical load), followed by cart stacking and shipping (both moderately heavy). The operations polythene bag filling and planting of seedlings into bags were classified as light physical effort.
\end{abstract}

Keyword: Forest ergonomics, planting and silviculture.

\footnotetext{
${ }^{1}$ Recebido em 07.02.2006 e aceito para publicação em 29.03.2007

${ }_{2}^{2}$ Departamento de Engenharia Florestal, Centro de Ciências Agrárias da UFES, 29500-000 Alegre-ES. E-mail:<fiedler@pq.cnpq.br>.

${ }_{3}^{3}$ Departamento de Engenharia Florestal da UNB. E-mail: <venturoli@ rudah.com.br>.

${ }^{3}$ Departamento de Engenharia Produção da UFV, 36570-000 Viçosa-MG. E-mail: <minetti@ufv.br>.
} 


\section{INTRODUÇÃO}

A produção de mudas em viveiros, segundo Martins et al. (1998), constitui a primeira etapa da atividade florestal e pode ser feita por meio da propagação por sementes ou vegetativa. Dependendo da maneira como são executadas essas operações e das condições de trabalho oferecidas, podem ocorrer diversas situações adversas ao bem-estar, à segurança e à saúde dos trabalhadores (ALVES, 2001).

Atualmente, com a maior competitividade do setor de produção de mudas, houve elevação do rendimento no trabalho. As atividades são realizadas, na maioria das vezes, por empresas privadas que, muitas vezes, visando à maximização dos lucros, redução dos custos e otimização da produção, acabam fazendo menor investimento no seu principal elemento de trabalho, ou seja, o trabalhador.

Esse aumento de produtividade sem melhoria nas condições de trabalho pode estar levando o indivíduo a trabalhar acima de seus limites físicos, adotar posturas potencialmente lesivas ao seu organismo e levantar e transportar cargas com pesos acima dos limites toleráveis, além de, freqüentemente, realizar essa movimentação de modo incorreto (FIEDLER, 1998; VENTUROLI, 2000).

A capacidade física do ser humano para desenvolver atividades pesadas em geral é muito baixa. Cabe ressaltar que o homem é uma máquina que consome energia, mesmo parado (COUTO, 1995). No entanto, na grande maioria das vezes a utilização de máquinas nas operações de propagação de mudas em viveiros tem uso apenas como auxílio no desempenho des tarefas. Em muitas atividades existe forte necessidade de uso dos sentidos como o tato e a visão.

A aplicação dos estudos ergonômicos nas operações de produção de mudas visa amenizar a fadiga física e mental dos trabalhadores e aumentar a satisfação, segurança e bem-estar, levando, conseqüentemente, à melhoria da qualidade e produtividade das mudas.

A avaliação da carga física de trabalho foi o primeiro parâmetro tratado pela fisiologia do trabalho e continua sendo uma questão central para a maioria dos trabalhadores do mundo (FIEDLER et al., 1998). A freqüência cardíaca é um importante indicador para avaliar a carga de trabalho, devido aos inúmeros conhecimentos adquiridos em fisiologia humana e à grande facilidade de registro dos dados (EDHOLM, 1968).

Segundo Iida (1990), determinado dispêndio energético pode causar diferentes exigências do sistema cardíaco, dependendo das condições como temperatura do ambiente, tipo de trabalho (estático ou dinâmico) e número de músculos envolvidos no trabalho dinâmico.

A avaliação da carga de trabalho físico nas atividades de produção de mudas, realizadas por métodos manuais e semimecanizados, e a conseqüente reorganização do trabalho com base nos limites permitidos podem levar a condições mais seguras e saudáveis no ambiente de trabalho, melhorando sensivelmente a adaptação da atividade à pessoa que a realiza e proporcionandolhe maior conforto, bem-estar, produtividade e qualidade do trabalho.

Esta pesquisa teve como objetivo avaliar a carga de trabalho físico exigido nas operações de produção de mudas ornamentais em um viveiro do Distrito Federal, visando à reorganização ergonômica e à melhoria dos níveis de segurança, saúde, bem-estar e satisfação dos trabalhadores.

\section{MATERIAL E MÉTODOS}

\subsection{Local de estudo}

O estudo foi desenvolvido nos meses de outubro de 2002 a janeiro de 2003 em um viveiro de produção de mudas ornamentais no Distrito Federal, localizado na cidade-satélite do Núcleo Bandeirante. A temperatura média no período de coleta de dados variou entre 18 e $32^{\circ} \mathrm{C}$, e a umidade relativa do ar oscilou entre 22 e $90 \%$.

A jornada de trabalho estava dividida em dois turnos: das 8 às $12 \mathrm{~h}$ e das 13 às $17 \mathrm{~h}$. A produção diária do viveiro era em torno de 100.000 mudas em recipientes plásticos $(13 \mathrm{~cm} \times 13 \mathrm{~cm}$ x $13 \mathrm{~cm})$. Cem funcionários, em média, trabalhavam na produção de mudas.

\subsection{Atividades analisadas}

Fizeram parte das análises as atividades de enchimento dos recipientes plásticos com substrato, abastecimento da carreta com esses recipientes, encanteiramento, plantio de mudas e expedição, como descrito nos tópicos a seguir. 


\subsubsection{Enchimento dos recipientes plásticos com substrato}

Esta etapa era realizada em um galpão aberto (Figura 1) e consistia no enchimento dos recipientes plásticos com substrato (terra com adição de NPK + calcário + matéria orgânica). Os recipientes plásticos tinham dimensões de $13 \mathrm{~cm}$ x $13 \mathrm{~cm} \times 13 \mathrm{~cm}$ e, depois de cheios, eram acondicionados em caixas plásticas para posterior transporte até os canteiros.

\subsubsection{Abastecimento da carreta com os recipientes plásticos}

Atividade na qual o trabalhador tinha como função a colocação das bandejas contendo os recipientes plásticos na carreta, que, posteriormente, transportavamnas para os canteiros (Figura 2).

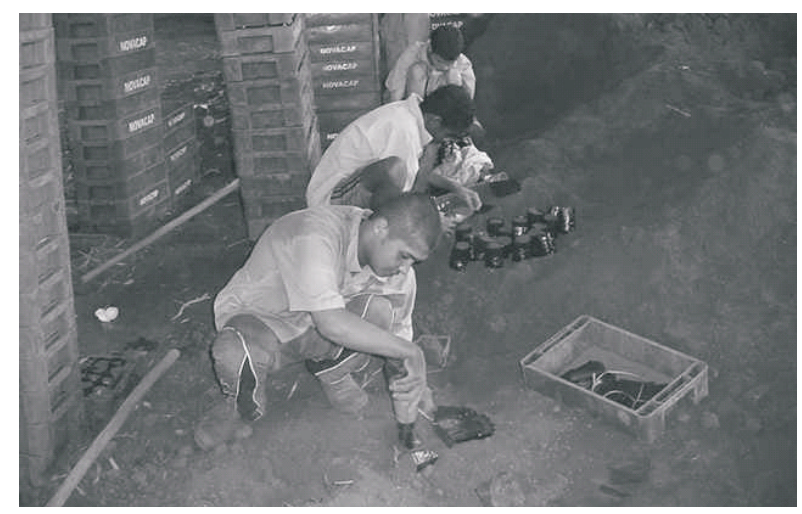

Figura 1 - Operação de enchimento dos recipientes plásticos com substrato.

Figure 1 - Polythene bag filling.

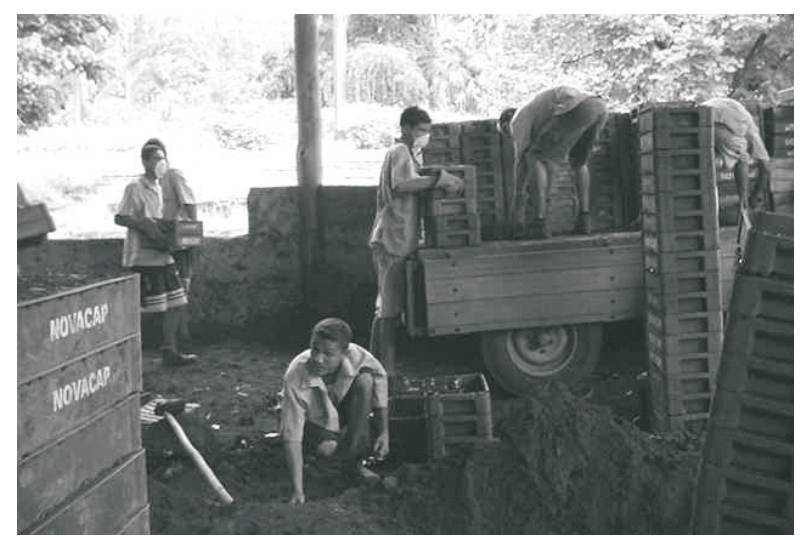

Figura 2-Abastecimento da carreta com os recipientes plásticos. Figure 2-Cart stacking.

\subsubsection{Encanteiramento}

No encanteiramento, o trabalhador retirava as bandejas com os recipientes plásticos da carreta e os organizava nos canteiros do viveiro ao nível do solo, conforme ilustrado na Figura 3.

\subsubsection{Plantio de mudas}

Etapa que consiste no plantio das mudas nos recipientes plásticos contendo substrato, nos canteiros (Figura 4).

\subsubsection{Expedição}

Nesta etapa os trabalhadores colocavam as mudas retiradas dos canteiros em bandejas de aço e levavamnas em seguida, para o caminhão, que fazia o transporte até os canteiros ornamentais da cidade (Figura 5).

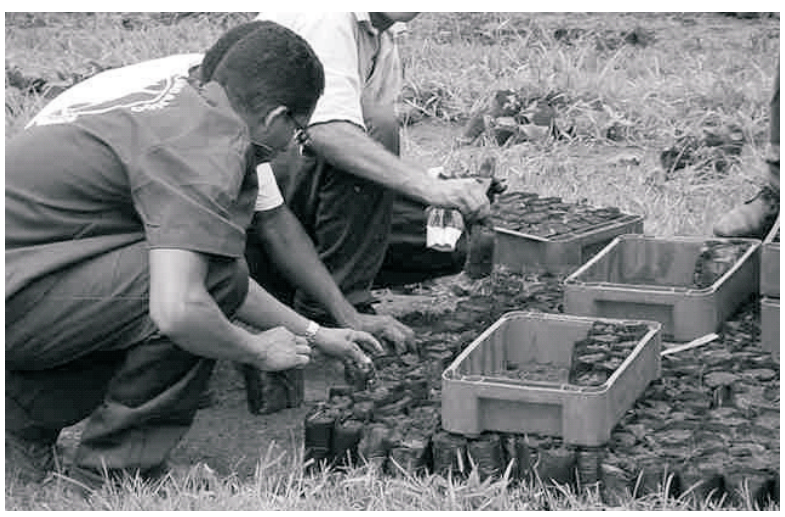

Figura 3 - Atividade de encanteiramento das mudas.

Figure 3-Transport of seedlings in polythene bags to nursery bed.

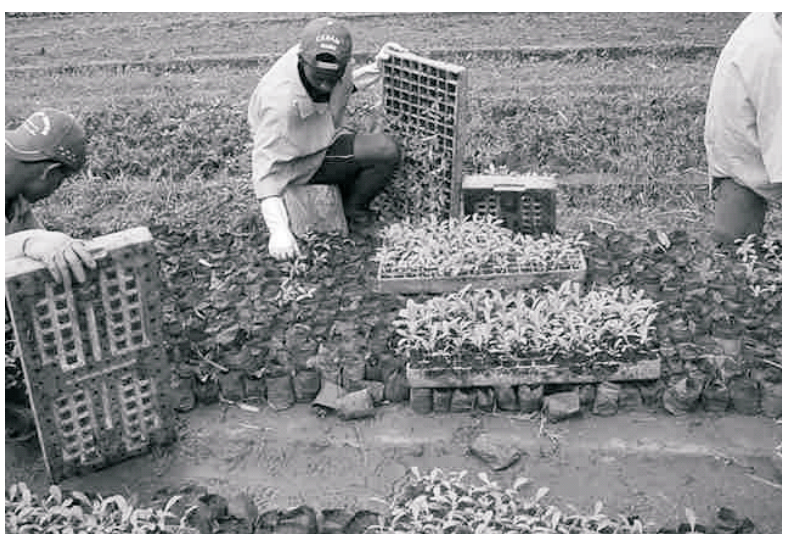

Figura 4 - Plantio de mudas nos recipientes plásticos. Figure 4-Planting of seedlings into bags.

R. Árvore, Viçosa-MG, v.31, n.4, p.703-708, 2007 


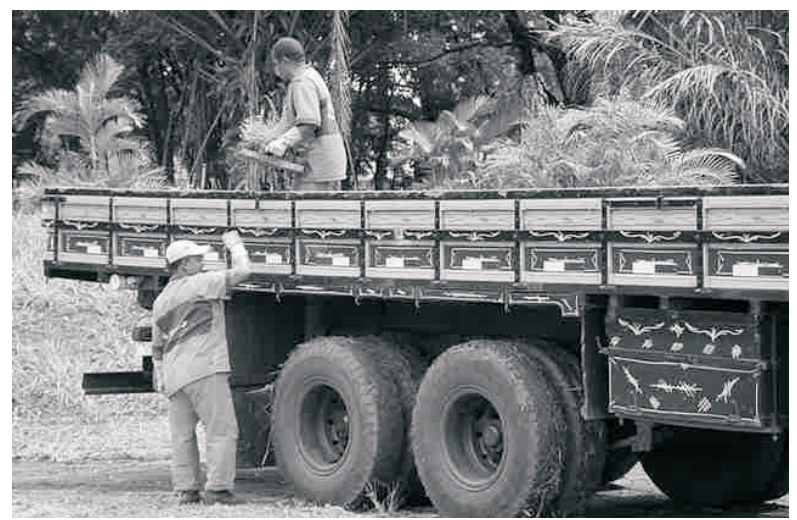

Figura 5 - Operação de expedição de mudas. Figure 5 - Shipping.

\subsection{Carga de trabalho físico}

A carga de trabalho físico foi avaliada por intermédio do levantamento da freqüência cardíaca nas diversas fases do ciclo de trabalho de cada atividade da produção de mudas. Os dados foram coletados e analisados pelo sistema da Polar Eletro 0y, da Finlândia. O equipamento é formado por um receptor digital de pulso, uma correia elástica e um transmissor com eletrodos que foram fixados na altura do tórax do trabalhador, por meio de uma correia elástica. Os batimentos cardíacos foram armazenados no receptor de pulso em intervalos de $15 \mathrm{seg}$. Após a coleta de dados, os valores foram transferidos para o computador com a utilização da interface que acompanha o equipamento e, por intermédio de software específico, foram realizadas as análises. Com esses dados, foi possível determinar a carga de trabalho físico imposta em cada operação e estabelecer os limites aceitáveis para um desempenho contínuo no trabalho, bem como ajustar a carga de trabalho físico à capacidade dos trabalhadores. Essa classificação laboral foi baseada na metodologia proposta por Apud (1997), dependente da freqüência cardíaca média por atividade durante a produção de mudas (Quadro 1).

Com essas análises foi possível calcular a carga cardiovascular no trabalho (APUD, 1997), que corresponde à frequiência cardíaca máxima utilizável. $O$ valor dessa carga foi calculado pela seguinte equação:

$$
\mathrm{CCV}=\underline{(\mathrm{FCT}-\mathrm{FCR})} \times 100
$$

em que:

$$
\mathrm{CCV}=\text { carga cardiovascular }(\%) ;
$$

R. Árvore, Viçosa-MG, v.31, n.4, p.703-708, 2007
FCT $=$ freqüência cardíaca de trabalho $(\mathrm{bpm})$;

$\mathrm{FCR}=$ freqüência cardíaca de repouso (bpm); e

FCM = frequiência cardíaca máxima (220 - idade em anos).

Para realização de um trabalho contínuo sem riscos para a saúde, a carga cardiovascular, segundo Apud (1997), não deve ser superior a $40 \%$ em um turno de trabalho de $8 \mathrm{~h}$. Nos casos em que a carga cardiovascular foi superior a esse valor, calculou-se a freqüência cardíaca limite (FCL) da seguinte forma:

$$
\mathrm{FCL}=0,40(\mathrm{FCM}-\mathrm{FCR})+\mathrm{FCR}
$$

Nas análises em que a carga cardiovascular ultrapassou esse valor de $40 \%$ para reorganização do trabalho, foi determinado o tempo de repouso (pausa) necessário pela seguinte equação:

\section{$\operatorname{Tr}=\underline{\mathrm{Ht}}(\mathrm{FCT}-\mathrm{FCL})$ \\ FCT - FCR}

em que:

$\operatorname{Tr}=$ tempo de repouso, descanso ou pausa, em $\min ; \mathrm{e}$

$\mathrm{Ht}=$ duração do trabalho, em min.

\subsection{Amostragem}

O número mínimo de repetições foi estabelecido considerando-se um erro de $5 \%$, a partir de uma amostragem-piloto utilizando a fórmula proposta por Conaw (1977):

Quadro 1 - Classificação da operação segundo a freqüência cardíaca média no trabalho

Table 1 -Classification of operation according to the cardiac frequency

\begin{tabular}{cc}
\hline $\begin{array}{c}\text { Frequencia Cardiaca } \\
\text { Média }(\mathrm{bpm})\end{array}$ & $\begin{array}{c}\text { Classificaçâo da } \\
\text { Atividade }\end{array}$ \\
\hline$<75$ & Muito leve \\
$75-100$ & Leve \\
$100-125$ & Moderadamente pesado \\
$125-150$ & Pesado \\
$>150$ & Extremamente pesado \\
\hline
\end{tabular}

Fonte: Apud, 1997. 


$$
\mathrm{n}>\frac{\mathrm{t}^{2 *} \mathrm{~s}^{2}}{\mathrm{e}^{2}}
$$

em que:

$\mathrm{n}=$ número de pessoas ou de repetições necessárias;

$\mathrm{t}=$ coeficiente tabelado a $95 \%$ de probabilidade (distribuição de Student);

$\mathrm{s}=$ desvio-padrão da amostra: $\mathrm{e}$

$\mathrm{e}=$ erro admissível $=5 \%$.

Pela amostragem-piloto realizada, recomenda-se um mínimo de 1.862 amostras por fase do ciclo de trabalho. A coleta de dados foi realizada com 14 trabalhadores amostrados aleatoriamente em cada uma das cinco etapas de produção de mudas, totalizando 70 pessoas. Como os dados de frequiência cardíaca eram coletados a cada $15 \mathrm{seg}$, totalizaram-se 2.600 amostras de freqüência cardíaca por trabalhador, perfazendo um total de 182.000 amostras. Em média, cada um dos 70 trabalhadores foi avaliado por $7,8 \mathrm{~h}$ de trabalho.

\section{RESULTADOS E DISCUSSÃO}

A Figura 6 ilustra os resultados das análises relativas à carga física de trabalho, classificada por atividade analisada durante a produção de mudas ornamentais.

A atividade considerada de maior exigência física foi o encanteiramento, classificada como pesada, seguida da expedição de mudas e abastecimento da carreta, classificadas como moderadamente pesadas. As atividades consideradas como pesadas ou moderadamente pesadas foram aquelas em que havia maior manuseio e movimentação de cargas durante o trabalho. Daí a sua maior exigência física.

No Quadro 2, apresentam-se os resultados por atividade analisada referentes à idade média dos trabalhadores, peso médio, estatura média, freqüência cardíaca média no trabalho, freqüência cardíaca média em repouso, freqüência cardíaca média máxima, carga cardiovascular, freqüência cardíaca limite, tempo de repouso necessário e classificação do trabalho.

A atividade considerada de maior exigência física foi o encanteiramento, classificada como pesada, seguida da expedição de mudas e abastecimento da carreta, classificadas como moderadamente pesadas. As atividades consideradas como pesadas ou moderadamente pesadas foram aquelas em que havia maior manuseioe movimentação de cargas durante o trabalho. Daí a sua maior exigência física.

No Quadro 2, apresentam-se os resultados por atividade analisada referentes à idade média dos trabalhadores, peso médio, estatura média, frequiência cardíaca média no trabalho, freqüência cardíaca média em repouso, frequiência cardíaca média máxima, carga cardiovascular, freqüência cardíaca limite, tempo de repouso necessário e classificação do trabalho.

Os resultados indicaram que a maior exigência física foi encontrada na atividade de encanteiramento, com freqüência cardíaca no trabalho de 126,3 bpm e carga cardiovascular de 50,9\%, portanto acima do limite máximo de $40 \%$. Para que a freqüência cardíaca não ultrapasse esse limite de $40 \%$, a freqüência cardíaca no trabalho não deve ultrapassar o limite de 114 bpm. Esse limite máximo provavelmente se conseguirá com um repouso médio de 12,8 min por hora trabalhada. As demais atividades não tiveram o limite de carga cardiovascular ultrapassado, portanto poderão ser executadas normalmente da maneira como se encontrava organizado o sistema de trabalho. Caso não seja possível a pausa de $12,8 \mathrm{~min}$ por hora no encanteiramento, para uma melhor performance no trabalho e menor desgaste físico dos trabalhadores sugere-se um rodízio entre os trabalhadores que executam as fases de maior e de menor exigência física.

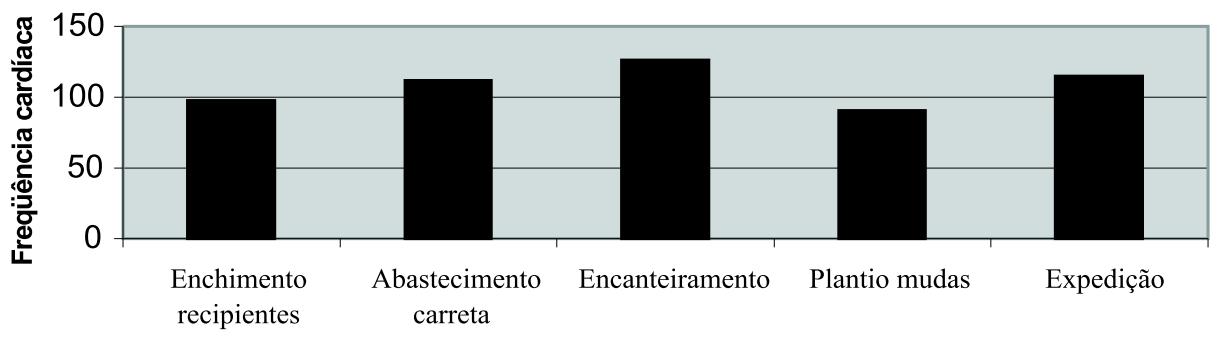

Atividades

Figura 6 - Carga física de trabalho por atividade analisada.

Figure 6 - Physical effort per analyzed operation. 
Quadro 2 - Avaliação da carga de trabalho físico exigido nas operações de produção de mudas Table 2 -Demanded physical effort in seedling production operations

\begin{tabular}{|c|c|c|c|c|c|c|c|c|c|c|}
\hline Atividade & $\begin{array}{l}\text { Idade média } \\
\text { (anos) }\end{array}$ & $\begin{array}{c}\text { Peso médio } \\
(\mathrm{kg})\end{array}$ & $\begin{array}{l}\text { Estatura } \\
\text { média }\end{array}$ & $\begin{array}{c}\text { FCT } \\
(\mathrm{bpm})\end{array}$ & $\begin{array}{c}\text { FCR } \\
(\mathrm{bpm})\end{array}$ & $\begin{array}{l}\mathrm{FCM} \\
(\mathrm{bpm})\end{array}$ & $\begin{array}{l}\mathrm{CCV} \\
(\%)\end{array}$ & $\begin{array}{c}\text { FCL } \\
(\mathrm{bpm})\end{array}$ & $\begin{array}{c}\operatorname{Tr} \\
\text { (min/hora) }\end{array}$ & $\begin{array}{l}\text { Classificação } \\
\text { do trabalho }\end{array}$ \\
\hline $\begin{array}{l}\text { Enchimento } \\
\text { dos recipientes }\end{array}$ & 18,5 & 72,25 & 172,6 & 97,9 & 67 & 201,5 & 23,0 & - & & Leve \\
\hline $\begin{array}{l}\text { Abastecimento } \\
\text { da carreta }\end{array}$ & 19,7 & 67,75 & 168,5 & 111,7 & 71 & 200,3 & 31,5 & - & & $\begin{array}{c}\text { Moderadamente } \\
\text { pesado }\end{array}$ \\
\hline Encanteiramento & 38,5 & 71,5 & 170,5 & 126,3 & 69 & 181,5 & 50,9 & 114 & 12,8 & Pesado \\
\hline Plantio de mudas & 19,25 & 68,25 & 169,7 & 90,7 & 67 & 200,7 & 17,8 & - & & Leve \\
\hline Expedição & 35,5 & 69,25 & 171,6 & 115,0 & 70 & 184,5 & 39,3 & - & & $\begin{array}{c}\text { Moderadamente } \\
\text { pesado }\end{array}$ \\
\hline
\end{tabular}

Em que: $\mathrm{FCT}$ = Freqüência cardíaca no trabalho; $\mathrm{FCR}=$ frequiência cardíaca em repouso; $\mathrm{FCM}=$ freqüência cardíaca máxima; $\mathrm{CCV}=$ carga cardiovascular $(\%) ; \mathrm{FCL}=$ freqüência cardíaca limite; e $\mathrm{Tr}=$ tempo de repouso necessário.

\section{CONCLUSÕES}

Os resultados desta pesquisa permitiram as seguintes conclusões:

- A atividade de maior exigência física foi o encanteiramento, classificado como pesado, com carga cardiovascular acima do limite máximo permitido, necessitando de um repouso de 12,8 min por hora trabalhada. As demais atividades não excederam os limites de carga cardiovascular.

- As atividades de expedição de mudas e abastecimento da carreta foram classificadas como de exigência física moderadamente pesada.

- Enchimento dos sacos plásticos e o plantio de mudas foram classificados como atividades de exigência física leve.

- Para uma melhor performance e menor desgaste físico dos trabalhadores, o sistema de trabalho deve ser reorganizado com o rodízio entre as atividades de maior e menor desgaste físico.

\section{REFERÊNCIAS}

ALVES, J. U. Análise ergonômica das atividades de propagação vegetativa de Eucalyptus spp. em viveiros. 2001. 90 f. Dissertação (Mestrado em Ciência Florestal) Universidade Federal de Viçosa, Viçosa, MG, 2001.

APUD, E. Temas de ergonomia aplicados al aumento de la productividad de la mano de obra en cosecha florestal. In: SIMPÓSIO BRASILEIRO SOBRE COLHEITAE TRANSPORTE FLORESTAL,3., Vitória, 1997. Anais... Vitória: SIF, 1997. p 46-60.

R. Árvore, Viçosa-MG, v.31, n.4, p.703-708, 2007
CONAW, P. L. Estatística. São Paulo: Edgard Blucher,.1977.264p.

COUTO, H. A. Ergonomia aplicada ao trabalho: o manual técnico da máquina humana. Belo Horizonte: Ergo, 1995. v.1. 353p.

EDHOLM, O. G. A biologia do trabalho.Porto: Inova, 1968. 258p.

FIEDLER, N. C. Analise de posturas e esforços despendidos em operações de colheita florestal no Litoral Norte do Estado da Bahia. 1998. 103f. Tese (Doutorado em Ciência Florestal) - Universidade Federal de Viçosa, Viçosa, MG, 1998.

FIEDLER, N. C. et al. Avaliação da carga de trabalho físico exigido em operações de colheita florestal. Revista Árvore, v.22, n.4, p.535-543, 1998.

IIDA, I. Ergonomia: projeto e produção. São Paulo: Edgard Blucher, 1990. 465p.

MARTINS, R. C. C.; JACINTO, J. M. M.; MARTINS, I. S. Viveiros florestais. Brasília: Universidade de Brasília, 1998. 22p.

VERDUSSEN, R. Ergonomia; a racionalização humanizada do trabalho. Rio de Janeiro: Livro Técnico e Cientifico, 1978. 162p.

VENTUROLI, F. Diagnóstico das condições de trabalho nas marcenarias do Distrito Federal. 2000. 56f. Trabalho final de curso (Graduação em Engenharia Florestal). Universidade de Brasília, Brasília, 2000. 